up a quarter of the mass of the Universe. Finally, one of the most sought-after targets is the Higgs boson, the only particle predicted by the standard model that has not yet been found. The elusive boson is a marker of the Higgs mechanism, which could explain how particles have mass.

\section{Bad welds}

The 2008 accident was caused by a faulty weld in a section of superconducting wire connecting two magnets. The subsequent months of inspections of the rest of the LHC found just four more bad welds in this type of connection - but also revealed a far more widespread problem.

The superconducting wires are surrounded by copper wires, which act as 'safety valves' to carry any sudden surge in current. The copper wire will only come into play if the superconducting wires warm up and lose their ability to conduct electricity without resistance.

Tests over the past few weeks have revealed 80 bad welds between sections of copper wire, but with roughly 10,000 copper-wire welds scattered around the LHC, not all have been inspected. This element of uncertainty means that CERN must increase the operating energy of the machine cautiously to avoid further accidents.

The cost of repairs so far is 40 million Swiss francs. Myers acknowledges there was a qualitycontrol problem with the welds, and that the systems for detecting current surges and mitigating a catastrophic release of helium could have been improved. "It's usually the simple things that cause you problems," he says.

Peter Limon, a physicist at Fermi National Accelerator Laboratory in Batavia, Illinois, says these birth pains are "typical". Limon points out that various problems meant that Fermilab's Tevatron - currently the world's highest-energy collider - took years to reach its maximum collision energy of $1.8 \mathrm{TeV}$. With a year or two of data collection needed for the LHC to make a definitive Higgs discovery, the Tevatron still has a chance at bagging it first. Tevatron physicists plan to present the latest update on their Higgs hunt on 18 August at the Lepton-Photon conference in Hamburg, Germany.

Gordon Kane, a theorist at the University of Michigan in Ann Arbor, says that the physics community is frustrated by delays at the LHC, but adds that an extra year is not so long to hold on for the Higgs particle, given that its existence was proposed in 1964. "I'm going to be there when it's discovered," says the 72-year-old Kane, "no matter how long it takes."

Eric Hand

For more on the LHC, see www.nature.com/lhc

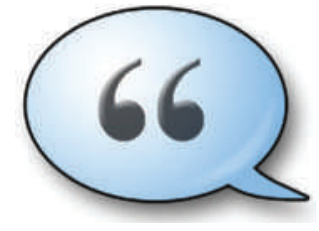

HAVE YOUR SAY

Comment on any of our News stories, online.

www.nature.com/news

\title{
Science advisers mull priorities
}

An elite group of 21 US researchers met publicly for the first time last week as the new advisory panel to US President Barack Obama on scientific and technical matters. But despite an enthusiastic inaugural meeting, it will take time to know how effective the President's Council of Advisors on Science and Technology (PCAST) will be.

PCAST has already put together its first report, on the government's H1N1 pandemic strategy. Other topics likely to be high on its agenda include how science can help the economic recovery, and how best to deliver on Obama's ambitious climate and energy research portfolio.

Opening the meeting on 6 August, co-chair John Holdren called the council "a spectacular cast of leaders of our science, technology and innovation communities". Holdren, who is Obama's chief science adviser, chairs PCAST with Harold Varmus, former director of the National Institutes of Health in Bethesda, Maryland, and Eric Lander, director of the Broad Institute in Cambridge, Massachusetts. The full group boasts three Nobel laureates and 16 members of the national academies of science, engineering or medicine.

The new PCAST "has a great membership and outstanding co-chairs, but its ability to influence events depends on who listens", cautions John Marburger, who co-chaired the previous incarnation of PCAST as the science adviser to President George W. Bush. PCAST's success or failure depends mainly on its access to the president and on its interactions with various other advisory groups within the administration. These include the Office of Science \& Technology Policy, which Holdren directs, and the National Science and Technology Council, composed mainly of the heads of agencies that deal with scientific matters, along with the US vice-president.

Last November, Marburger and the other outgoing PCAST co-chair, venture capitalist Floyd Kvamme, left a memo offering their successors some advice, including limiting the number of members: under Bush, the council launched in December 2001 with 24 members and expanded to 35 in 2005. PCAST's previous incarnation focused more on technology advice, and it included fewer academic scientists and more business executives.

"The best thing about this PCAST is that it's up and running earlier in the term than the previous one," says Marburger. At the meeting last week, Holdren said that the council's speedy formation was a clear signal that Obama thinks that science and technology are crucial in addressing global challenges. On 7 August, the council met with the president for a little over an hour.

PCAST's H1N1 report had been commissioned by Obama in late June. Shortly after, the council met for two days with around a dozen experts in public health, virology and other key fields. The report, which has not yet been made public, was delivered two weeks later and addressed the value of scenario planning, communicating complex messages to the public and policy-makers, and the types of legal, social, financial and other factors that could get in the way of responding to a pandemic. "Everyone felt that it was probably the best response ever to an epidemic event," says Lander.

Last week's meeting saw council members suggesting future subjects that could attract their scrutiny. Barbara Schaal, a plant geneticist at Washington University in St Louis, suggested weighing in on the research agenda for the proposed National Institute for Food and Agriculture, an institute authorized within the US Department of Agriculture but not yet funded. Lander, also a geneticist, suggested looking at governmental approaches to cancer research, including evaluating whether the most creative approaches get support in their early days. And geochemist Daniel Schrag of Harvard University suggested tackling national strategies for research into adaptation to cope with the effects of climate change. The next PCAST meeting is slated for late October.

Alexandra Witze and Lizzie Buchen

See Editorial, page 781. 